Faculty and

PostDoc,

Energy,

Environment \&

Resource

Sustainability

\section{PREPARATION OF SLIPPERY LIQUID INFUSED POROUS SURFACES ON POLYMERIC SUBSTRATES}

Anton Popelka, Salma Habib, Aya Abusrafa, Fathima Sifani Zavahir, Asma Abdulkareem

Center for Advanced Materials, Qatar University, P.O. Box 2713, Doha, Qatar

E-mail: anton.popelka@qu.edu.qa

\title{
INTRODUCTION
}

Many polymers have been found in bio-science paralleling with advancement in a technology sector [1,2]. A selection of suitable polymers for using in a biomedical sector is based on many factors such as chemical nature, surface free energy or morphology, which influence cell-polymer surface interactions [3]. However, these materials suffering from infections represent serious issues for their applications [4]. These infections closely relate with biofilm formation, whereby microorganisms are strongly attached to surface forming strong attached multicellular communities [5]. Therefore, a preparation of slippery liquid infused porous surfaces (SLIPS) using low-temperature plasma technique in combination with electrospinning technique was utilized in this research. A multistep physicochemical approach was carried out for this purpose. The first step includes the pre-treatment of polyethylene (PE) and polyurethane (PU) substrates using low-temperature plasma to activate the surface for an adhesion improvement. Subsequently, the 3D porous network consisted of superhydrophobic fiber mats was fabricated on the plasma activated substrates using electrospinning technique. Final step consisted of the infusion of naturally oils with emphasis on their antimicrobial effect. This complex strategy led to the effective antimicrobial modification of the PE and PU surface potentially applicable in the biomedical field.

\section{ANTIMICROBIAL MODIFICATION}
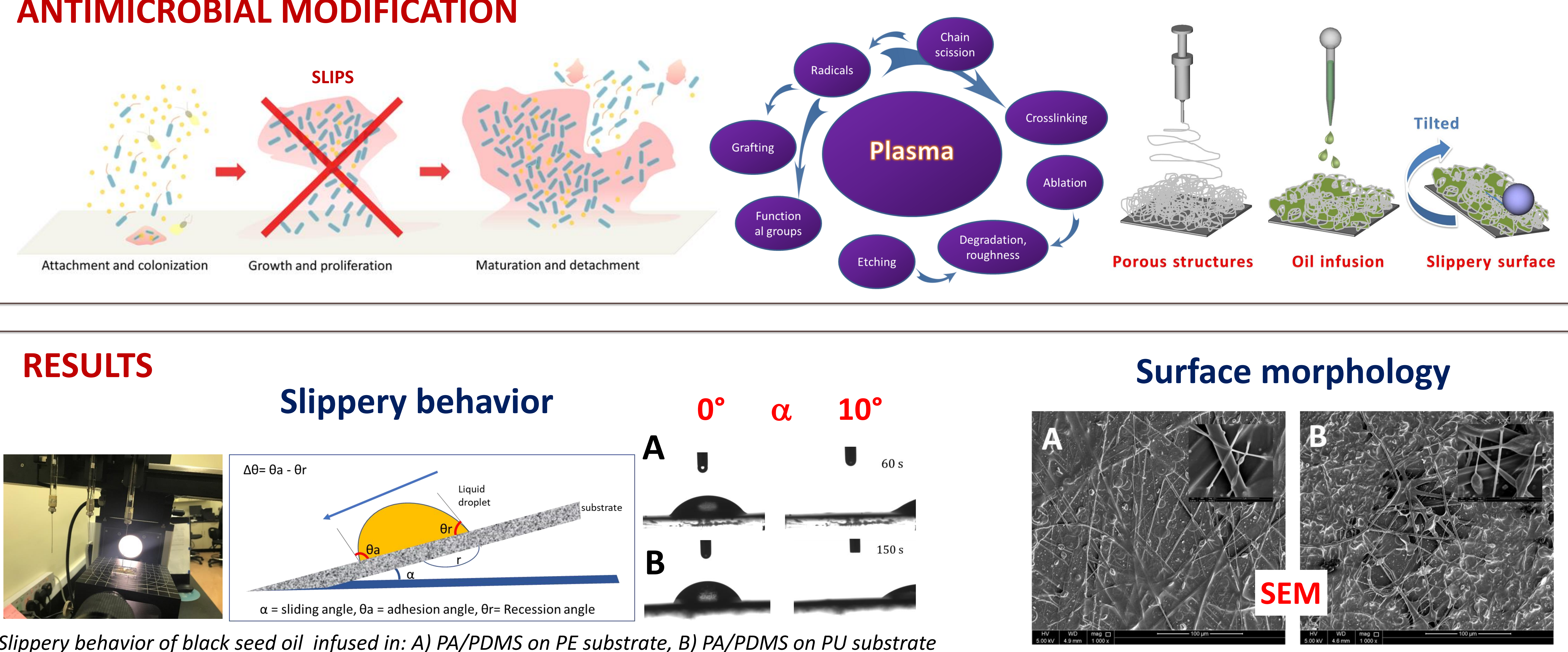

\section{Antimicrobial activity}

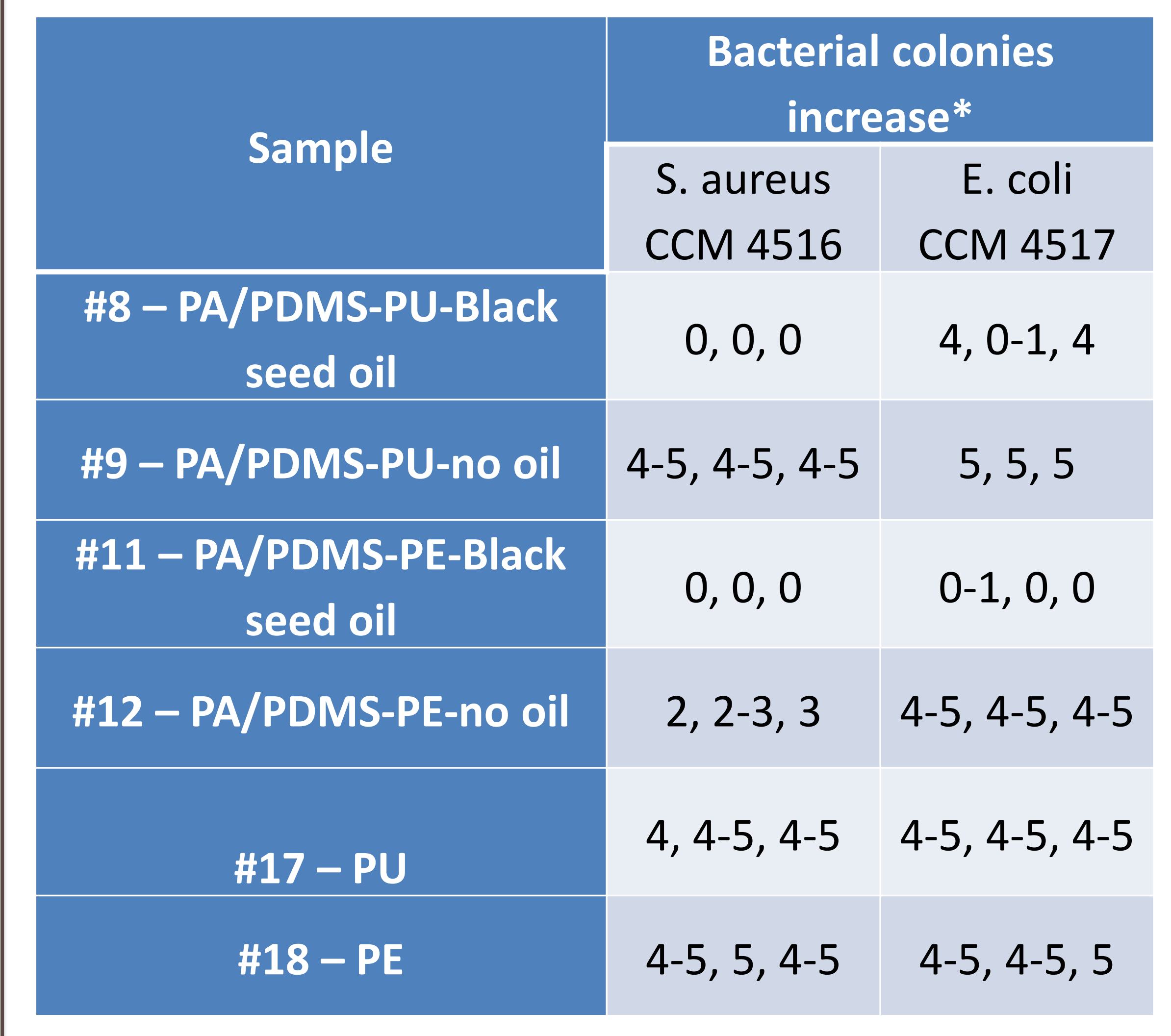

The scale for assessing the growth of bacterial colonies:

0-without growth, 1-deductible amount (single colony), 2-deductible amount (combined colony), 3-second imprint:

distinguishable colonies, third imprint can be deducted, 4-third imprint: distinguishable colonies, 5-overgrown: continuous growth
Surface morphology

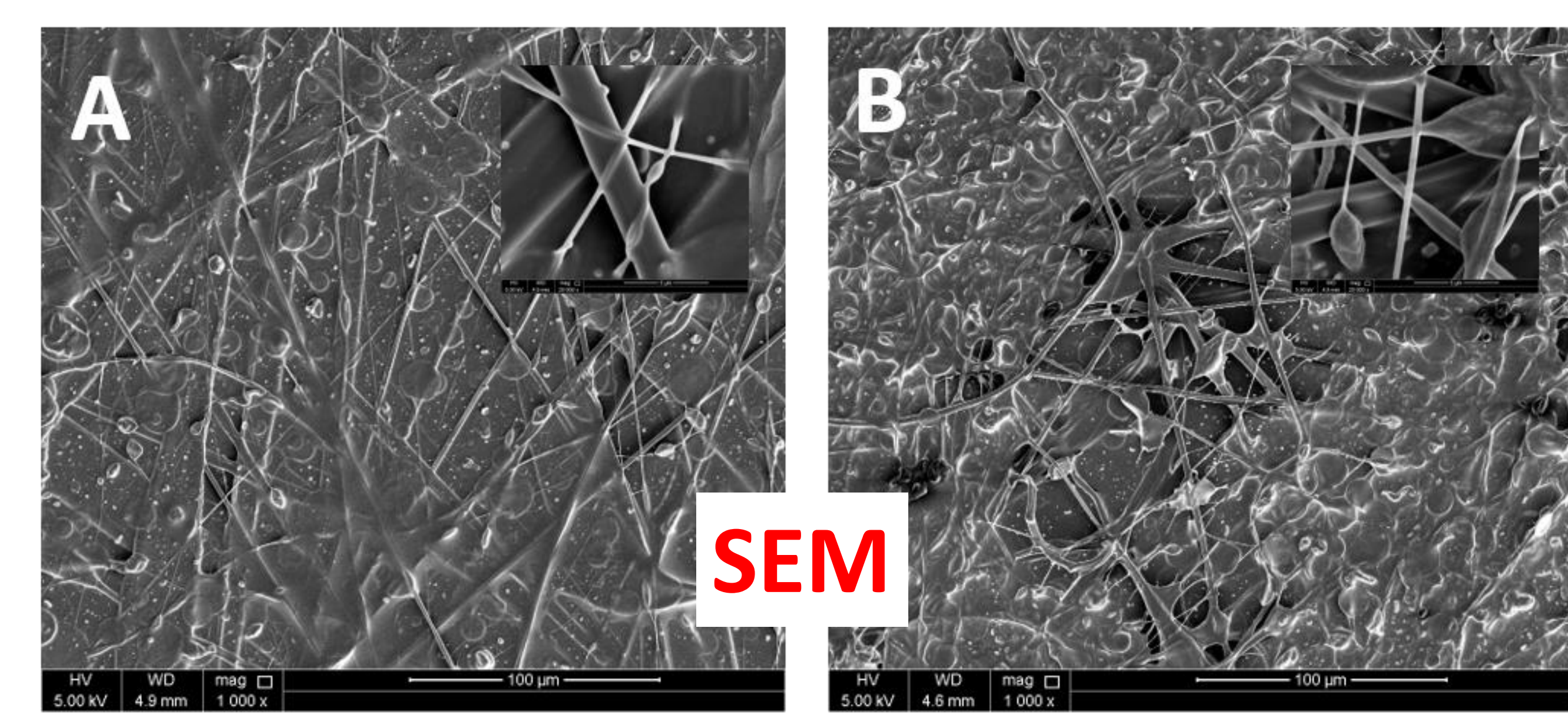

A

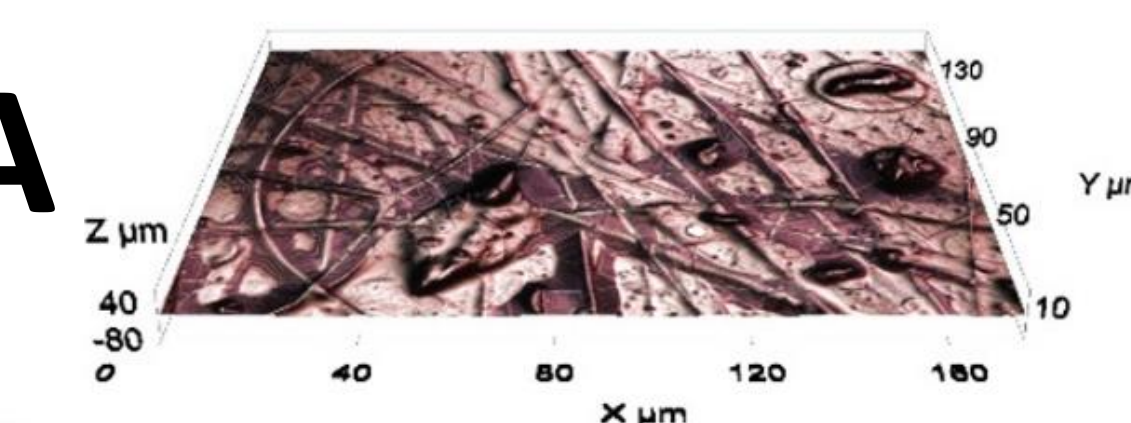

\section{ACKNOWLEDGEMENT}

This publication was made possible by an Award JSREP 07-022-3-010 from the Qatar National Research Fund (a member of The Qatar Foundation). The statements made herein are solely the responsibility of the authors.

\section{CONCLUSIONS}

- Electrospinning technology was successfully used for fabrication of PA/PDMS nanoporous structures on PE and PU substrates.

- Black seed oil infusion was responsible for slippery behavior.

- Antimicrobial activity was proved after black seed oil infusion into PA/PMDS against gram-positive $S$. aureus and gram negative E. coli bacteria strains.

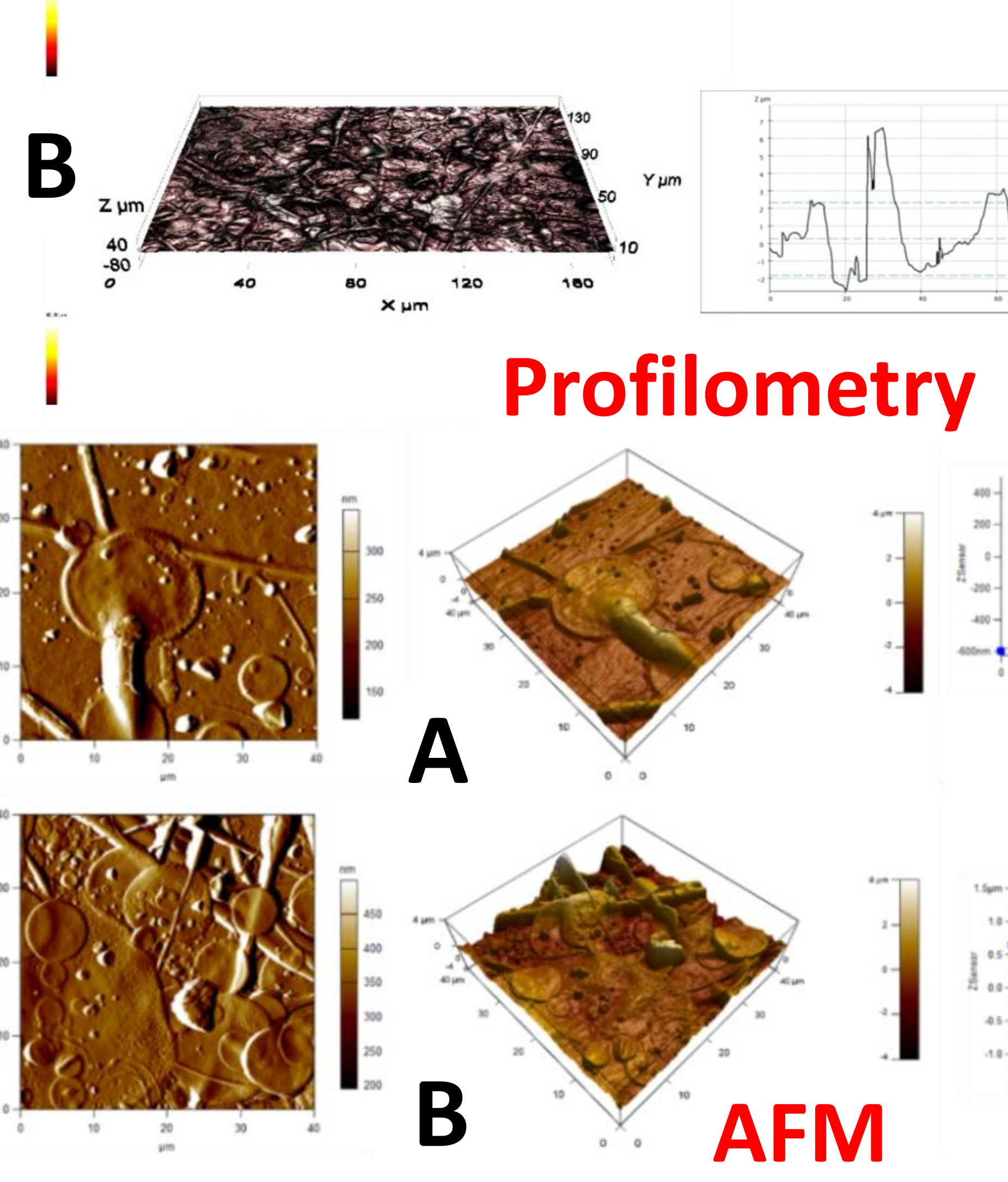

Microscopic images of black seed oil infused in PA/PDMS on A) PE substrate, B) PU substrate

\section{REFERENCES}

[1] James N.R., Jayakrishnan J.A. Biomaterials 2003 24, 2205.

[2] Lakshmi S., Kumar S.S.P., Jayakrishnan J.A. J. Biomed. Mater. Res. 2002, 61, 26.

[3] Gomathi N., Sureshkumar A., Neogi S. Curr. Sci. India 2008, 94, 1478.

[4] Kenawy E.R., Worley S.D., Brighton R. Biomacromolecules 2007, 8, 1359.

[5] O'Toole G., Kaplan H.B., Kolter R. Annu. Rev. Microbiol. 2000, 54, 49 